\title{
Tongue protrusion as an indicator of vital burning
}

\author{
Herman Bernitz ${ }^{1}$, Paul van Staden ${ }^{2}$, Christine M. Cronjé ${ }^{3}$, René Sutherland ${ }^{1}$
}

Corresponding author: Prof Herman Bernitz, Department of Oral Pathology and Oral Biology, School of Dentistry, University of Pretoria, P.O. Box 1266, Pretoria, 0001 Tel.:+27 84 5125258; Fax.:+27 13 2826489; bernitz@iafrica.com

\footnotetext{
${ }^{1}$ Department of Oral Pathology and Oral Biology, School of Dentistry, University of Pretoria, Pretoria, South Africa

${ }^{2}$ Department of Statistics, University of Pretoria, Pretoria, South Africa

${ }^{3}$ Department of Forensic Medicine, Faculty of Health Sciences, University of

Pretoria, Pretoria, South Africa
}

Running header: Tongue protrusion, indicator of vital burning

\begin{abstract}
In the forensic assessment of burned bodies, the question of whether the victim was exposed to the fire before of after death is of crucial importance. Several external signs have been used in the past to indicate heat exposure prior to the death of the victim but these did not include tongue protrusion. The internal signs of heat exposure are generally regarded as much more important than those observed externally. No one factor has been found to be totally reliable. This study found a statistically significant dependence between tongue protrusion and presence soot in the respiratory tract and stomach, the later being a good indicator of vital burning. The results of this study confirm that tongue protrusion can be used as an additional indicator of vital burning.
\end{abstract}

Keywords Forensic science · Forensic pathology Forensic odontology · Vital burning · Tongue protrusion

\section{Introduction}

In the forensic assessment of burned bodies, the question whether the victim was exposed to the fire before or after death is of crucial importance [1]. The circumstances surrounding the heat exposure episode are vital when trying to establishing if the victim's demise was an accident, a crime or a suicide [2]. Several external signs have been used in the past to indicate heat exposure prior to the death of the victim. These external signs have included skin blisters coupled with an inflammatory reaction, lack of soot deposits at the corners of the eyes, incompletely singed eyelashes and petechial haemorrhages in the conjunctivae [1-3]. The internal signs of heat 
exposure are generally regarded as more important than those observed externally [1-6]. These include soot deposits in the respiratory tract, oesophagus and stomach, oedematous swelling and vesicular detachment of the mucosa in the pharynx and larynx as well as high blood level values for carboxyhemoglobin $(\mathrm{COHb})$ and hydrogen cyanide (HCN) [1,2,4,5,6]. Hirsch et. al. in a 1969 publication questioned the reliability of increased $\mathrm{COHb}$ as being definitive of vital burning [7]. The importance of $\mathrm{COHb}$ has recently been highlighted by several authors, and is considered an important indicator of vital burning [8-9].

Yonemitsu et.al. demonstrated that volatile hydrocarbons in post mortem blood could assist in classifying the type of fire present at the time of death as well as showing a correlation with $\mathrm{COHb}$ concentrations [10] Yonomitsu et.al. also found soot to be the best indicator of death by fire [10].

Severely burnt corpses generally require dental identification which is carried out by a forensic odontologist [11]. The position of the tongue, either protruded beyond the dental arches or within the occluded dental arches, would be visible during the forensic dental examination. Botha [12] made mention of a protruded tongue observed in a victim who had died during a fire, but did not speculate whether it was as a result of vital burning or not. Protrusion of the tongue from the open mouth of fire victims has been attributed to the heat-related shrinkage of the soft tissue of the neck [13]. Several other authorities have postulated that reflex laryngospasm induced by air temperatures of $>150^{\circ} \mathrm{C}$ and hyperventilation could be considered initiating factors of tongue protrusion [14-18]. A significant number of cases in which the cause of death was reported as manual or ligature strangulation by hanging, presented with protruded tongues[19-20]. Gross tongue haemorrhages observed in a significant number of strangulation cases are considered to have contributed to the tongue protrusion present [19]. Homicidal strangulation concealed by burning could thus present with a protruded tongue in a case of nonvital burning [21].

The aim of this study was to investigate whether tongue protrusion could be used as an additional tool when determining if an individual had succumbed as a result of vital burning.

\section{Materials and methods}

One hundred and seven severely burned corpses were examined at the Medico Legal Laboratory in Pretoria during the period January 2007 to December 2009. The sample consisted of 74 males and 33 females between the ages of 2 months and 86 years (Fig 1). The ethnicity of the victims was broadly representative of demographics of the country: 98 blacks, 2 Asians and 7 whites. The study only included severely charred 


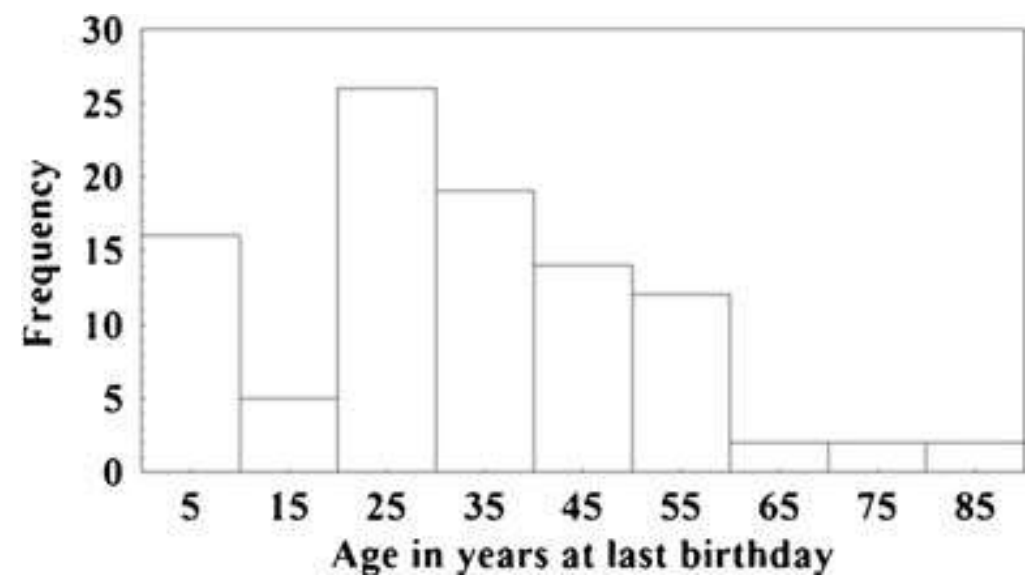

Fig. 1 Histogram of the age in years of burn victims

victims who succumbed at the scene of the incident and whose cause of death was documented as "Death by fire", and included the parameters documented in Table 1. A severely charred corpse was defined as one in

Table 1 Circumstances of death by fire

\begin{tabular}{|l|c|}
\hline Parameter & Number of cases \\
\hline Veld fire & 3 \\
\hline Suicide with accelerators & 3 \\
\hline Shack fire & 52 \\
\hline Caravan accident & 1 \\
\hline Murder-set alight with accelerators & 6 \\
\hline Apartment fire & 6 \\
\hline Car accident & 6 \\
\hline Electrocution & 1 \\
\hline House fire & 6 \\
\hline Burned-cause unknown & 10 \\
\hline Gas cylinder explosion & 1 \\
\hline Aircraft accident & 12 \\
\hline ITAL & 107 \\
\hline
\end{tabular}

which visual identification was no longer possible (unrecognisable). During the routine examination of the charred bodies, the position of the tongue was documented in the forensic pathological examination of the remains. The position of the tongue was recorded as protruded or non-protruded. A protruded tongue was defined as one which extended beyond the dental arches with the teeth separated. A non-protruded tongue was defined as one positioned within the occluded dental arches. Edentulous victims were excluded from this study. The tongue position was then compared with three other parameters routinely used, namely $\mathrm{COHb}$ concentrations in the blood, HCN concentrations in the blood and soot deposition in the trachea, bronchi, oesophagus and stomach. This scientific research project was approved by the ethics committee of the University of Pretoria. 


\section{Results}

Tongue protrusion beyond the dental arch was documented in 63 of the 107 victims. In 27 of the 107 cases the tongue position was documented as not protruded. In 11 cases no information regarding the tongue position was recorded. In 6 cases the tongue position could not be established as a result of anterior facial destruction, and was documented as such.

Soot deposits were present in the respiratory tract, the oesophagus or stomach of 96 of the 107 victims. No soot was present in 8 cases, while in 3 cases the consumption of the corpse by fire made soot analysis impossible. In the 8 cases in which no soot was present, 1 presented with tongue protrusion, 2 had no tongue protrusion, 1 tongue was completely destroyed and in 4 cases no information regarding the tongue position was documented. The relationship between the position of the tongue, and the absence or presence of soot deposits, is illustrated in Fig 2. Using Fisher's exact test, the null hypothesis of no dependence between the tongue position and the presence or absence of soot deposits, was tested against the one-sided alternative that tongue protrusion beyond the dental arch coincides with the presence of soot deposits. The resulting $p$-value was 0.03 , leading to a conclusion of a statistically significant relationship between tongue protrusion and soot deposition. The corresponding estimated odds ratio was $(61 / 2) /(24 / 5)=6.35$ with a $95 \%$ Wald confidence interval of $(1.15$, $35.01)$

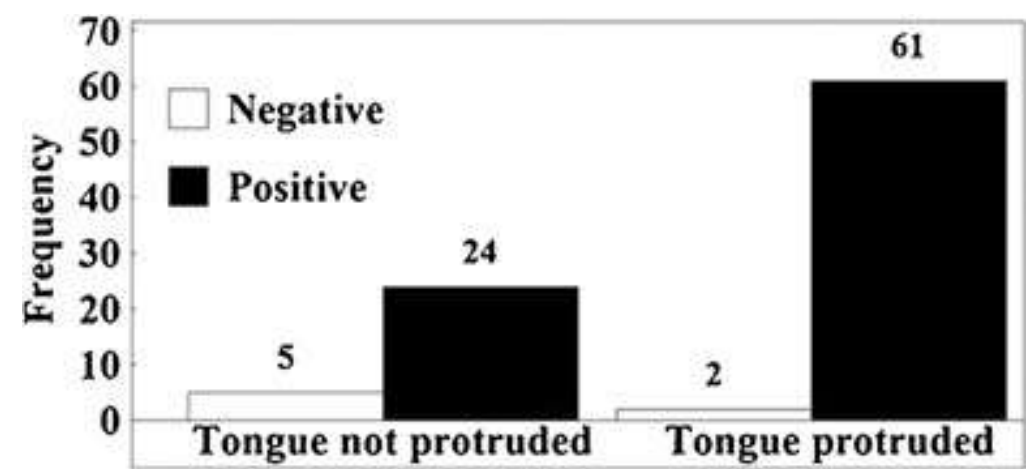

Fig. 2 Bar chart of the relation between the position of the tongue and the absence and presence of soot deposits (negative or positive) in burn victims

$\mathrm{COHb}$ levels were recorded as \% COHb concentrations in 85 of the 107 cases. In 2 of the cases the COHb was only stated as being at a level of $<20 \%$. The distribution of the measured $\mathrm{COHb} \%$ concentration is shown in Fig 3. The average $\mathrm{COHb} \%$ concentration for these 83 victims was $31.2 \%$ with a standard deviation of $22.6 \%$. 
In victims with the tongue protruded, the average and median $\mathrm{COHb}$ were $32.42 \%$ and $26.13 \%$ respectively, whereas for victims with the tongue not protruded, the average and median were $28.27 \%$ and $18.55 \%$. The Mann-Whitney test with a $p$-value of 0.24 indicated no significant statistical difference with respect to the

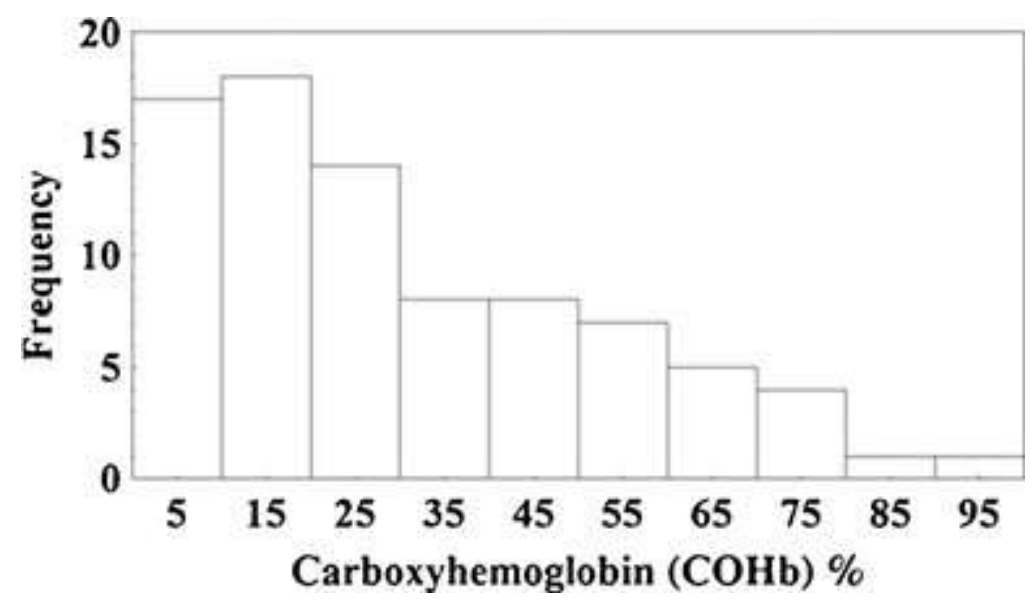

Fig. 3 Histogram of the carboxyhaemoglobin $(\mathrm{COHb}) \%$ concentrations for burn victims

median $\mathrm{COHb} \%$ concentration between victims with the tongue protruded or not protruded. Furthermore, the Kolmogorov-Smirnov two-sample test with an asymptotic $p$-value of 0.43 indicated no significant difference in terms of statistical distribution between the two groups. However, as shown in Fig 4, the $\mathrm{COHb} \%$ concentrations for nearly a third of the 22 victims with the tongue not protruded, that is 7 victims, were less than $10 \%$, whereas the $\mathrm{COHb} \%$ concentrations were less than $10 \%$ for only 8 of the 52 victims with the tongue protruded. Fisher's exact test was therefore performed to determine whether victims with the tongue not protruded are more likely to have $\mathrm{COHb} \%$ concentrations less than $10 \%$ compared to victims with the tongue protruded. The $p$-value of 0.1004 implied no significant dependence between the position of the tongue and $\mathrm{COHb} \%$ levels.

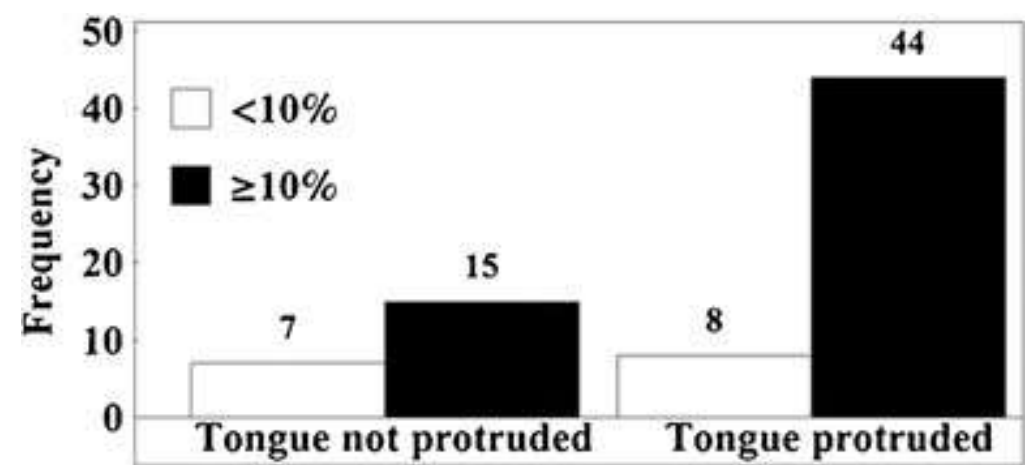

Fig. 4 Bar chart of the relation between the position of the tongue and carboxyhaemoglobin $(\mathrm{COHb}) \%$ concentrations $(<10 \%$ or $\geq 10 \%)$ for burn victims 
Hydrogen cyanide was measured in only 72 cases; levels varied from undetectable to $5200 \mu \mathrm{g} / \mathrm{l}$, with a mean of 344. $6 \mu \mathrm{g} / \mathrm{l}$ and standard deviation of 918.8 .

\section{Discussion}

The extent of burns in victims of "death by fire" frequently renders the victim unrecognisable, and identification by forensic odontologists using scientific methods which include comparisons of ante-mortem and post-mortem dental records, is required. The first author, who routinely identifies victims of fire, observed that tongue protrusion was present in many burned victims, especially those later found to have perished as a result of vital burning. The results of this research indicate that there is a statistically significant dependence between soot deposition and tongue protrusion. The importance of this correlation is highlighted by Yonomitsu et.al. who found soot to be the most significant indicator of death by fire, as smoke contains large quantities of soot which can easily be inhaled. [10]. Soot deposits were present in 61 of the 63 victims who showed tongue protrusion beyond the dental arch. The calculated odds ratio suggests that the presence of a protruded tongue is 6.35 times more likely to occur when soot particles are present than when soot particles are not present. The results of this research do not conclusively correlate non-protrusion to non-vital burning. This research showed a stronger interdependence between soot and tongue protrusion than between $\mathrm{COHb}$ and tongue protrusion, which tends to confirm that soot is a more reliable indicator of vital burning than $\mathrm{COHb}$. The fact that different $\mathrm{COHb}$ thresholds were used to determine positive values makes this analysis less reliable. Generally, a threshold of $>10 \%$ is considered positive for inhalation as result of fire. However, statistical analyses showed no significant relationship between tongue position and $\mathrm{COHb} \%$ concentration.

In this study, HCN levels were not measured in all of the cases. The fact that many bodies were transported over long distances to the forensic mortuary, and that there was often a long delay between time of death and autopsy, made accurate measurement of this unstable toxic gas with a half-life of one hour, unreliable [8]. Table 1 illustrates that a large number of the victims were burned in shack fires; in this scenario, one would expect to find less "modern" cyanide-forming materials, and thus negative HCN results [8]. The large standard deviation of results obtained demonstrate the problematic nature of interpretation of HCN levels. The results of the HCN analysis were thus excluded from the data set. 
There were no cases in this study of victims who had died as a result of strangulation by hanging followed by burning. The fact that strangulation by hanging could cause tongue protrusion must be considered when such a victim is later exposed to fire. Tongue protrusion in these cases would certainly not indicate vital burning.

Further research, using a larger sample is required to determine if a non protruded tongue can in fact indicate non vital burning. The exact physiological mechanism involved in causing the tongue to protrude in cases of vital burning should also be investigated.

\section{Conclusion}

A detailed review of the literature revealed that this is the first study dealing exclusively with implications of tongue protrusion in burned bodies. The presence of tongue protrusion in a victim consumed by fire was found to be indicative of vital burning, except in cases of strangulation or hanging followed by burning. Tongue protrusion should be considered together with all the other known signs when determining the possibility of vital burning in cases of death by fire.

\section{References}

1. Bohnert M, Werner CR, Pollak S (2003) Problems associated with the diagnosis of vitality in burned bodies. Forensic Sci Int 135:197-205

2. Fanton L, Jdeed K, Tilhet-Coartet S, Malicier (2005) Criminal burning. Forensic Sci Int 158:87-93

3. Janssen W (1984) Injuries caused by heat and cold. Forensic histopathology. Springer, Berlin

4. Canfield DV, Chaturvedi AK, Dubowski KM (2005) Carboxyhemoglobin and blood cyanide concentrations in relation to aviation accidents. Aviat Space Environ Med 76:978-980

5. Rogde S, Olving JH (1996) Characteristics of fire victims in different sorts of fire. Forensic Sci Int 77:93-99 
6. Gerling I, Meissner C, Reiter A, Oehmichen M (2001) Death from thermal effects and burns. Forensic Sci Int 115:33-41

7. Hirsch CS, Adelson L (1969) Absence of carboxyhemoglobin in flash fire victims. J Am Med Assoc 210:2279-2280

8. Stamyr K, Thelander G, Ernstgård L, Ahlner J, Johanson G (2012) Swedish forensic data 1992-2009 suggest hydrogen cyanide as an important cause of death in fire victims. Inhal Toxicol 24:194-199

9. Grabowska T, Skowronek R, Nowicka J, Sybirska H (2012) Prevalence of hydrogen cyanide and carboxyheamoglobin in victims of smoke inhalation during enclosed-space fires: a combined toxicological risk. Clin Toxicol 50:759-763

10. Yonemitsu K, Sasao A, Oshima T, Mimasaka S, Ohtsu Y, Nishitani Y (2012) Quantitative evaluation of volatile hydrocarbons in post-mortem blood in forensic autopsy cases of fire-related deaths. Forensic Sci Int 217:71-75

11. Keiser-Nielsen S (1980) Person identification by means of the teeth, a practical guide. John Wright \& Sons Ltd, Bristol

12. Botha CT (1985) The role of the tongue in forensic Odontology: A case report. J Forensic Odontostomatol 3:39-42

13. Bohnert M (2009) Injury: Burns, Scalds, and Chemical. Wiley encyclopaedia of forensic science. John Wiley \& Sons, Chichester

14. Anderson RA, Watson AA, Harland WA (1981) Fire deaths in the Glasglow area: 1 General considerations and pathology. Med Sci Law 21:175-190 
15. Purser DA, Grimshaw P, Berrill KR (1984) Intoxication by cyanide in fires: A study in monkeys using polyacrylonitrile. Arch Environ Health 39:394-400

16. Heimbach DM, Waeckerle JF (1988) Inhalation injuries. Ann Emerg Med 17:1315-1318

17. Sant' Ambroglio G, Mathew OP (1986) Laryngeal receptors and their reflex responses. Clin Chest Med $7: 11-22$

18. White SM (2002) Cannabis abuse and laryngospasm. Anaesthesia 57:606-625.

19. Bockholdt T, Maxeiner H (2002) Hemorrhages of the tongue in postmortem diagnostics of strangulation. Forensic Sci Int 126:214-20.

20. Duband S, Timoshenko AP, Morrison AL, Prades J, Debout M, Peoc'h M (2009) Ear bleeding: A sign not to be under estimated in cases of strangulation. Am J Forensic Med Pathol 30:175-6.

21. Suárez-Peńaranda JM, Muńoz JI, De Abajo BL, Vieira DN, Rico R, Alvarez T, Concheiro L (1999) Concealed homicidal strangulation by burning. Am J Forensic Med Pathol 20:141-44. 